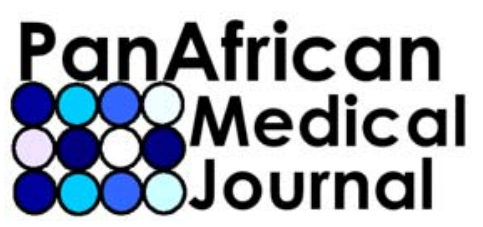

Provisional PDF

Published 14 March 2010

Case report, Volume 4, I ssue 11, 2010

\title{
Non-Hodgkin's lymphoma revealed by an ilio-colic intussusception in a Moroccan patient: a case report
}

\section{Karim I bn Majdoub Hassani ${ }^{1, \&}$, Hicham El bouhaddouti ${ }^{2}$, Abdelmalek Ousadden ${ }^{2}$, Amal Ankouz $^{2}$, Meryem Boubou ${ }^{3}$, Siham Tizniti ${ }^{3}$, Khalid Mazaz ${ }^{1}$, Khalid Ait Taleb ${ }^{2}$}

${ }^{1}$ Department of general surgery (B), University hospital Hassan II, Fes, Morocco, ${ }^{2}$ Department of general surgery (A). University hospital Hassan II. Fes, Morocco, ${ }^{3}$ Department of Radiology, Universitet hospital Hassan II, Fes, Morocco

\section{${ }^{\&}$ Corresponding author}

Ibn Majdoub Hassani Karim, 16, Rue Dominique, AV abi horayra, Zohor I, 30000, Fez, Morrocco. Tel: 00212665600722. Email: ibnmajdoubkarim@gmail.com

\section{Abstract}

Intussusceptions are rare but well-known causes of the small bowel obstruction in adults and an underlying cause is present in the majority of cases. Lymphoma's involvement of the ileum is one of the rare causes of intussusception. СT is a sensitive examination that diagnoses intussusceptions and provides an excellent preoperative evaluation including possible extension and dissemination especially in intestinal lymphomas. The treatment is almost always surgical and the pathological study is needed for diagnostic confirmation. Authors present an unusual case of intestinal intussusception due to lymphoma of the terminal part of the ileum in a 49year-old man. Computed tomography confirmed the diagnosis of intussusception and non-Hodgkin's lymphoma of B-cell was diagnosed by histological examination after surgical treatment. Primary intestinal lymphomas differ from gastric lymphomas in clinical features, treatment, and prognosis. They are not well characterized and the standardized concepts for their clinical diagnosis and management are absent. The aim of this rare observation is to shed light on NHL of the small bowel, its clinical and radiological diagnosis and its treatment especially in forms revealed by intussusceptions in adults. 


\section{Introduction}

An Intussusception is defined as the telescoping of one segment of the gastrointestinal tract into an adjacent one. It is a relatively a common entity in childhood in which it is presented as an acute illness. Most cases in childhood occur idiopathically. In adults, an underlying cause is present in $80 \%$ of cases. These causes include malignant process, lipomas and polyps as well as oedema and fibrosis from recent or previous surgery. Authors present an unusual case of intestinal intussusception due to a primary non-Hodgkin lymphoma (NHL) of B-cell of the terminal part of ileum. The primary ileal localization of $\mathrm{NHL}$ is rare, it occurs 23 to $30 \%$ of gastrointestinal lymphomas and approximately $5 \%$ of peripheral NHL [1]. It differs from gastric lymphomas in clinical features, treatment, and prognosis. Although substantial progress has been achieved in the diagnosis and treatment of gastric lymphomas in recent years $[2,3]$ primary intestinal lymphomas are not well characterized, and standardized concepts for their clinical diagnosis and management are absent. The aim of this observation is to shed light on NHL of the small bowel, its clinical and radiological diagnosis and its treatment especially in forms revealed by intussusceptions in adults.

\section{Patient and case report}

A fourty nine-aged Moroccan patient with a medical history of repeated abdominal cramping pain especially in the right iliac fossa and a constipation of 1 year's duration, was presented to the emergency department because of a three days history of incomplete intestinal obstruction with an acute abdominal pain cramp-like localized in the right iliac fossa with no particular radiation and no aggravating factor. He had no fever, no vomiting and no bleeding. The patient was not using any specific medication. His medical history did not suggest any major disease, as well. He had no prior history of abdominal surgery or trauma.

The physical examination revealed a conscious man whose temperature was $37^{\circ} \mathrm{C}$, a pulse rate 90 beat per minute (bpm), a blood pressure $120 / 70 \mathrm{~mm} \mathrm{Hg}$. The abdominal examination revealed tenderness with a large not reducible mobile mass measuring approximately $12 \mathrm{~cm}$ in the right iliac fossa. There was no liver enlargement and no splenomegaly or lyphadenopathy. A rectal examination showed no stool. Vital signs and the remaining of the physical examination were normal. Initial management of the patient involved intravenous fluid resuscitation, nasogastric tube insertion, routine bloods, supine chest and abdominal $x$-rays.

Laboratory data revealed a hematocrit of $31 \%$, hemoglobin of $10,6 \mathrm{~g} / \mathrm{dl}$, white blood cells of 10100 elements $/ \mathrm{mm}^{3}$, a blood urea of $0,25 \mathrm{~g} / \mathrm{L}$, and a creatinine level of $10 \mathrm{mg} / \mathrm{L}$. Coagulation, lipase, and Liver enzymes laboratory data were normal. A chest radiograph showed clear lung fields. A supine 
abdominal x-ray revealed multiple dilated small-bowel loops with air-fluid levels, but with no free air. Ultrasonography (US) of the abdomen revealed a typical image of an intussusception in the right iliac fossa with dilated small bowel loops and no free intra-abdominal fluid.

Abdominal computed tomography (CT) confirmed results of US and concluded to an ileocaecal intussusception (Figure 1). Based on the imaging findings, we made a decision to perform a laparotomy. During the surgical exploration, the peritoneal cavity was filled with $200 \mathrm{cc}$ of bloodstained serous fluid while numerous dilated loops of small bowel were present. There was an ileo-colic intussusception of $14 \mathrm{~cm}$ in length realizing a large mass of the right iliac fossa. There was no mesenteric adenopathies. An ileo-coecal enbloc resection was performed with continuity restored by ileo-colic end-to-end anastomosis (Figure 2). The specimen examination revealed a tumor of the terminal part of ileum with no mesenteric adenopathies. No complications occurred and the patient was discharged on the fifth day postoperatively.

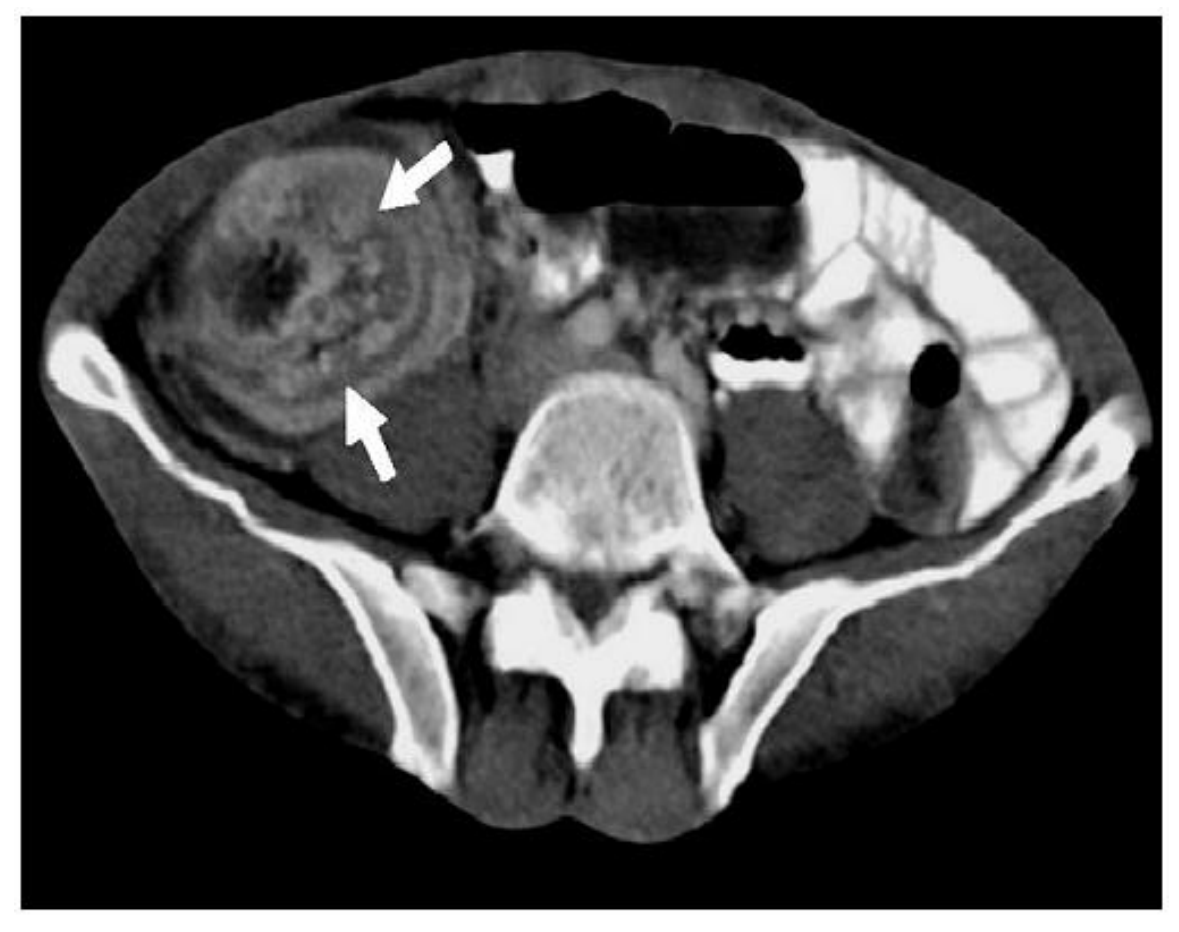

\section{Figure 1}

CT with Intravenous contrast material, showed a round mass lesion of soft tissue with fatty tissue within it in the right liac fossa. This soft tissue strands within the fat represent mesenteric blood vessels within the invaginated mesenteric fat. Some dilatation of the small bowel is also seen

Histological examination of the specimen demonstrated non-Hodgkin's lymphoma of the diffuse large B-cell type ( B-Cell NHL) which has a uniform, round-to-oval nuclei with vesicular chromatin and one or multiple conspicuous nucleoli (Figure 3). Cells were positive for B-cell marker $(C D 20+)$ at the 
immunohistochemical study (Figure 4). The disease was staged as primary ileal Stage 1 disease according to the Ann-Arbor classification. A postoperative chemotherapy (CHOP-R) stands for cyclophosphamide, hydroxydaunorubicin (Adriamycin), Oncovin (vincristine), and prednisolone combined with the monoclonal antibody rituximab was recommended but refused by the patient.

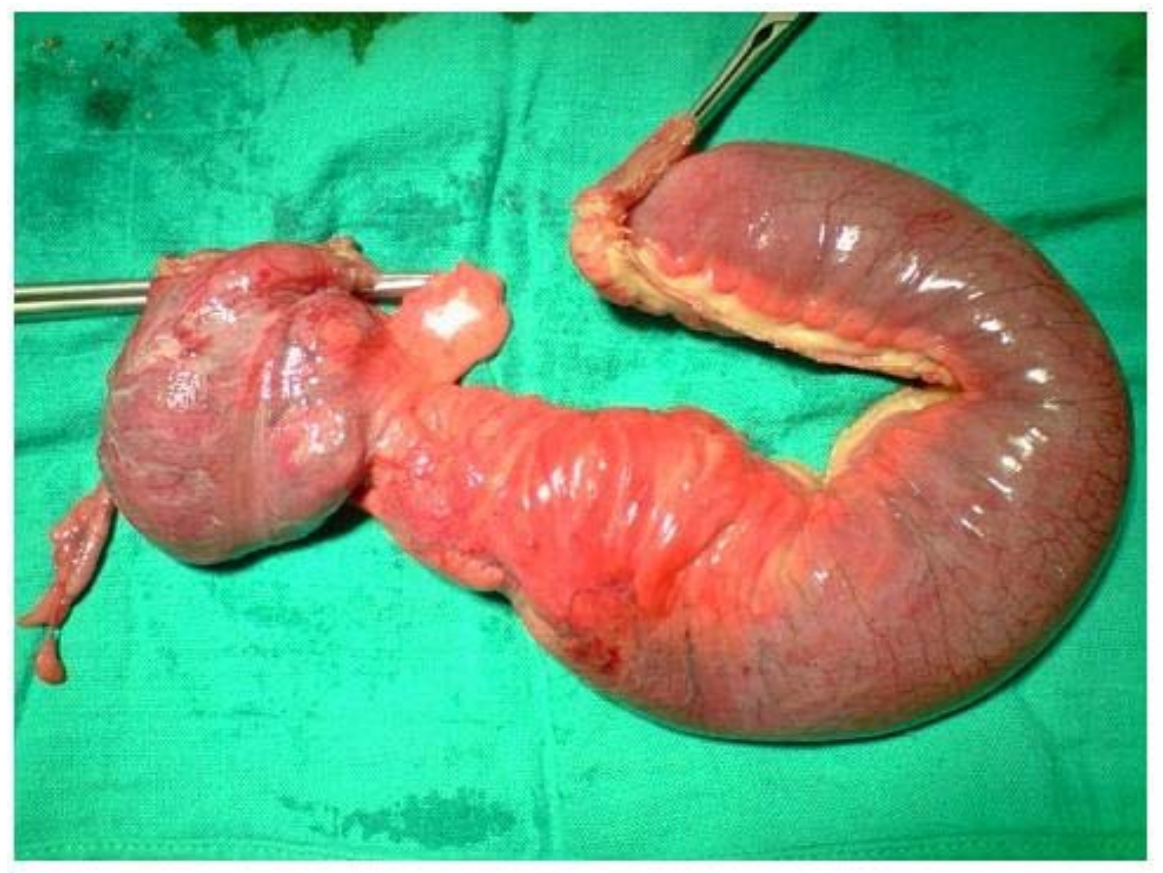

Figure 2

Specimen of the ileo-ceacal resection

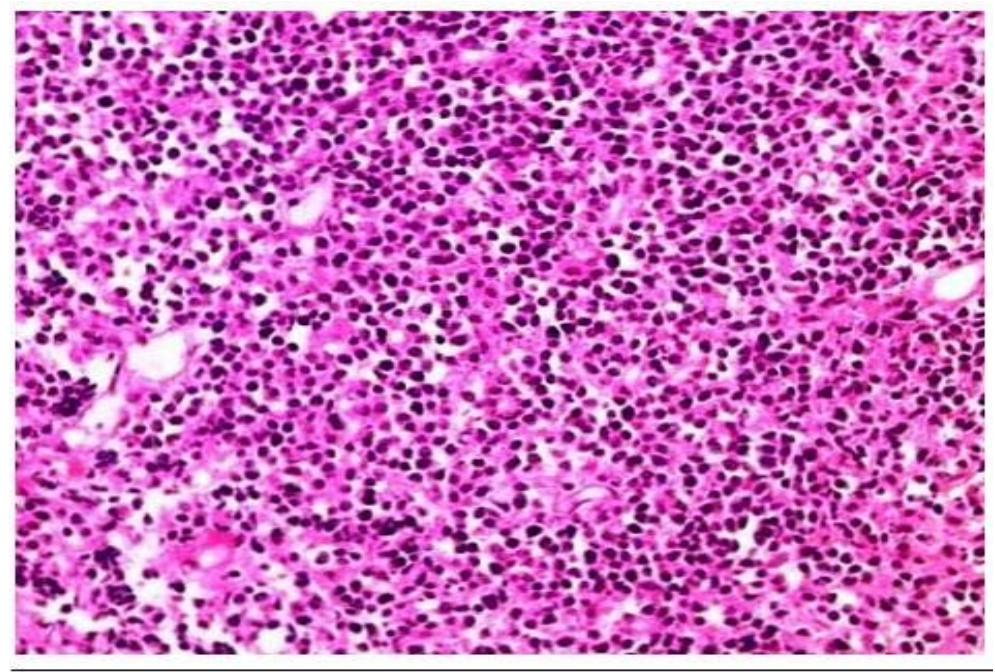

Figure 3

Histological examination demonstrating non-Hodgkin's lymphoma of the diffuse large B-cell type, which has uniform, round-to-oval nuclei with vesicular chromatin and one or multiple conspicuous nucleoli $(\times 200)$. 


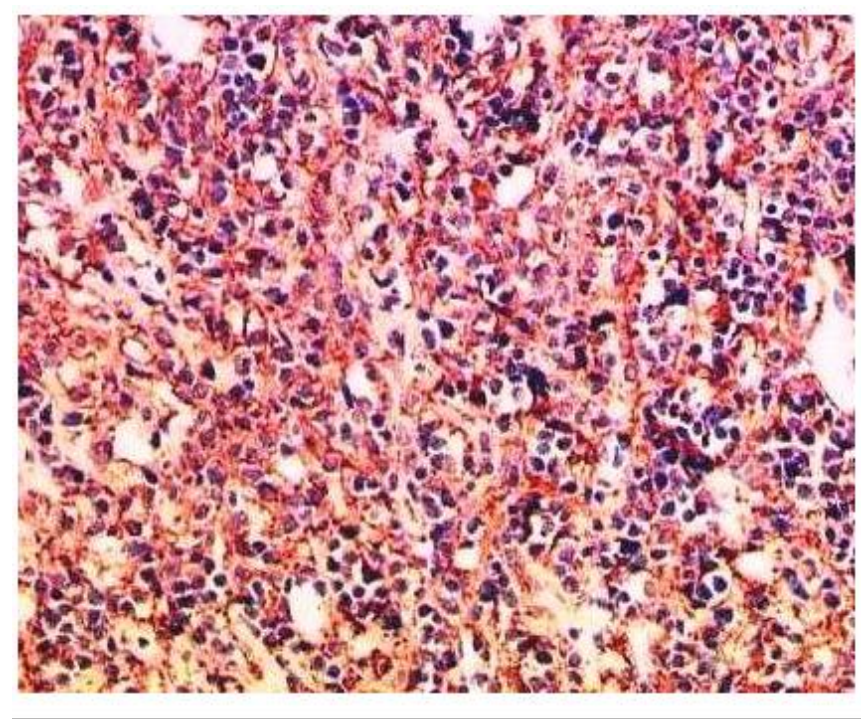

Figure 4

Photomicrograph showing cells positive for B-cell marker $(\mathrm{CD} 20+)$ at the immunohistochemical study $(\times 200)$

\section{Discussion}

Intussusception is a rare disease in adults when compared with children; one case of adult intussusception for every 20 childhood ones [4]. In infants, intussusceptions are primitive in the majority of cases [5]; however, in adults, an organic lesion is found in $80 \%$ of cases mostly in the benign and malignant disease in the ileum and the colon. These organic lesions are represented by the Gastro intestinal stromal tumors (GIST), lipomas, polyps or adenopathies especially in the ileocaecal localization.

More rare are intussusceptions caused by lymphoma's involvement of the ileum. Few cases were reported in the literature [6]. Small bowel lymphomas are rare due to several reasons [7]; however, the incidence of this disease has been rising in recent years particularly among immunocompromised patients $[8,9]$. Associations of small bowel B-cell lymphomas with post-transplantation, inflammatory bowel disease and some immunodeficiency syndromes have been reported [10, 11]. Nevertheless, one of the particularities of our case is that the medical history of our patient did not suggest any one of these diseases or syndromes. Intestinal T-cell non Hodgkin's lymphomas (T-Cell NHL) have been described as often multifocal and most frequently localized in the jejunum or proximal ileum. Many cases of association of intestinal T-Cell NHL to the celiac disease have been reported [1]. The primary follicular lymphoma of the small intestine is a distinct entity that originates from local antigenresponsive $B$ cells whereas little is known about the pathogenesis of primary small bowel lymphoma. 
A wide range of clinical presentations can occur for primary small bowel non-Hodgkin's lymphoma [12] including non-specific abdominal pain, ileus and weight loss. Diarrhea and fever are present in approximately one third of patients with T-Cell NHL but are rare in patients with B-Cell NHL [1]. Abdominal palpable mass is found in only $15 \%$ of cases [13]. Acute surgical conditions, such as perforation, bleeding and obstruction especially intussusseption -which is the case of our patient- are initial complications which can be the revealing mode of the small bowel lymphomas. These initial complications occurred up to $70 \%$ of cases in recent prospective studies; the predominant complications in patients with B-Cell NHL and T-Cell NHL were intestinal obstruction and perforation, respectively [1].

Concerning the intestinal intussusceptions, it is defined by the telescoping and penetration of an intestinal segment in the downstream segment. I ts evolutionary mode is usually sub-acute or chronic. Anatomically, in adults and regardless of the cause, the ileum is regarded as a preferential area of intussusceptions. The colo-colic intussusceptions present only $27 \%$ of cases and the colorectal forms are more rare [14]. The hyperperistaltism result from the presence of a pedunculated or nonpedunculated mass acted on an intestinal segment. Hyperperistaltism would be triggered by neurovegetatif reflexes and would be responsible for the formation of the width of intussusception which is the anatomicofunctional condition for the establishment of intussusceptions $[15,16]$.

Radiological diagnosis of intussusception especially the ileo-ceocal one caused by lymphoma can be suspected in ultra sonography (US) which can show a typical image of intussuception, but the computed tomography (CT) appearance of it is characteristic. It helps diagnose obstructive syndrome, its mechanism, the presence of the intussusception, its precise location and show its causes. It can also detect the organic cause in $71 \%$ of cases [17]. The most common finding in CT is a thickened segment of bowel with an eccentrically placed crescent-like fatty area, representing the intussusception and the intussuscepted mesentery. They appear either as a round target mass or as an oblong sausage shaped mass. Another common finding is a rim-shaped accumulation of contrast material in the periphery of the mass. In addition, air bubbles in the uppermost part of the intussusception can be observed in some cases [18].The role of CT is more important in cases of suspected abdominal lymphoma and polyps. It can objective a thickening of the wall associated with digestive adenopathies in lymphoma or a tissue density in the event of polyp.

Appropriate management of primary small bowel lymphoma is, therefore, still under discussion. One aspect of this discussion is that the surgical approach is necessary. Another aspect is that surgery is necessary but in combination with chemotherapy. According to few cases and to the absence of randomized trials in primary small bowel lymphoma, the optimal treatment strategy is not known [6]. However, the treatment of intussusceptions is always surgical and the resection may be necessary to some extent [19]. If contraindications of laparoscopy are not present, laparoscopic resection can be performed safely and should be considered for diagnosis and treatment for intussusception in 
ileoceacal lesions in adults. The most important rule in treatment is the avoidance of tumor emboli spread during manipulation [20]. If the primary small bowel lymphoma is diagnosed before or at laparotomy, surgical resection should be preferred in order to limit the risk of serious complications, such as perforation, bleeding and obstruction. In early-stage patients, complete resection surgery is more advantageous in some reports [21-23].

After the surgery, not only can the histological diagnosis of the lymphomas be established but also accurate staging can be made. Chemotherapy and radiotherapy have been used either alone or in combination with surgery [24]. Some other studies do not support the need for radiotherapy in intestinal B-cell lymphoma patients [6]. The results have not been evaluated adequately and the efficacy of these procedures is not known yet. Treatment strategies for primary small bowel lymphoma have been established but the debate about them persists [25]. However Radical tumor resectability had a highly significant effect on survival. In addition surgery in combination with chemotherapy was superior to any other treatment combination in localized disease and in disseminated cases [6]. Unfortunately, our patient refused post operative chemotherapy.

\section{Conclusion}

In small case series, few retrospective studies of small bowel lymphomas have been reported. In recent years some progress has been achieved in the diagnosis and treatment of gastric lymphomas, but the primary small bowel lymphomas are not well characterized and there is little information on their clinical diagnosis and management. However the treatment of ileal NHL revealed by intussusceptions in adults should always be surgical but preferably in combination with chemotherapy.

\section{Competing interests}

The authors declare that they have no competing interests.

\section{Consent}

Written informed consent was obtained for publication of this case report and accompanying images.

\section{Authors' contribution}

KIM is a surgeon who was drafting the manuscript and revising it critically for content. HE, AA and AO were involved in literature research and were major contributors in writing the manuscript. $\mathbf{K M}$, 
KA were surgeons treating of the patient and were involved in revising the draft critically for content.

MB and ST realized US and interpreted CT of the patient. All authors read and approved the final manuscript.

\section{References}

1. Daum S, Ullrich R, Heise W, Dederke B, Foss H-D, Stein H, Thiel E, Zeitz M and Riecken E-O.Intestinal Non-Hodgkin's Lymphoma : A Multicenter Prospective Clinical Study From the German Study Group on Intestinal Non-Hodgkin's Lymphoma.J ournal of Clinical Oncology.2003; 21(14):2740-2746. This article on PubMed

2. Fischbach $W$, Dragosics $B$, Kolve-Goebeler $M-E$, et al.Primary gastric B-cell lymphoma: Results of a prospective multicenter study.Gastroenterology.2000;119:1191-1202. This article on PubMed

3. Raderer M, Valencak J, O" sterreicher C, et al.Chemotherapy for the treatment of patients with primary high grade gastric B-cell lymphoma of modified Ann Arbor stages IE and IIE.Cancer.2000;88:1979-1985. This article on PubMed

4. Rathore MA, Andrabi SI, Mansha M.Adult intussusception--a surgical dilemma.J Ayub Med Coll Abbottabad.2006; 18(3):3-6. This article on PubMed

5. Sanogo ZZ, Yena S, Soumare S.Invagination intestinale aigue de l'adulte à propos de trois cas. Mali medical.2003; 19(12)

6. L Yin, CQ Chen, CH Peng, GM Chen, HJ Zhou, BS Han and HW Li.Primary Small-bowel Non-Hodgkin's Lymphoma: a Study of Clinical Features, Pathology, Management and Prognosis. The J ournal of International Medical Research.2007; 35: 406 - 415. This article on PubMed

7. Ahmed S, Singh A, Krauss J, et al.Successful treatment of refractory low grade duodenallymphoma with rituximab, an anti-CD20 monoclonal antibody.Am J Clin Oncol.2003; 26: 408 - 410. This article on PubMed

8. Nalesnik MA, Jaffe R, Starzl TE.The pathology of post-transplant lymphoproliferative disorders occurring in the setting of cyclosporine A-prednisone immunosuppression.Am J Pathol.1988; 133: 173 - 192. This article on PubMed

9. Bende RJ, Smit LA, Bossenbroek JG, et al.Primary follicular lymphoma of the small intestine: alpha4beta7 expression and immunoglobulin configuration suggest an origin from local antigenexperienced B cells.Am J Pathol.2003; 162: 105 - 113. This article on PubMed

10. DeMario M, Liebowitz D.Lymphomas in the immunocompromised patient.Semin Oncol.1998; 25: 492 502. This article on PubMed

11. Loftus $E$, Tremaine W, Habermann T, et al.Risk of lymphoma in inflammatory bowel disease.Am J Gastroenterol.2000; 95: 2308 - 2312. This article on PubMed 
12. Chim CS, Loong $F$, Leung AY, et al.Primary follicular lymphoma of the small intestine.Leuk Lymphoma.2004; 45: 1463 - 1466. This article on PubMed

13. Ramia J M, Sancho E, Lozano O, Santos J M, Garrido F.Primary small bowel lymphoma.Cir Esp.2007; 81(1):46-8. This article on PubMed

14. Minodier P, Merrot T.Invagination intestinale aigue de l'enfant.Mt pédiatrie.2006; 9

15. Bazzocchi R, Palmieri V, Lafratta V, Cavallotti M, Barbieri C.Ileo-ceco-colic invagination-Apropos of a case caused by lymphoma of the last ileal loop.Minerva Chir.1980;35(17):1295-302. This article on PubMed

16. Just $P A$, Hoang $C$, Cadi $M$, Capron F.Invagination intestinale aigue de cause inhabituelle.Gastroenterol Clin Biol.2005; 29 : 1160-1163. This article on PubMed

17. Ross GJ .J ejunojejunal intussusception secondary to a lipoma.Radiol.2000; 216: 727-30

18. G Gayer, S Apter, C Hofmann, S Nass, M Amitai, R Zissin.Intussusception in Adults: CT Diagnosis.Clinical Radiology.1998;53:53-57. This article on PubMed

19. Ribault L.Les invaginations intestinales aigues de l'adulte.Méd Afrique noire.1991; 38 (6)

20. Ishibashi Y, Yamamoto S, Yamada Y, Fujita S, Akasu T, Moriya Y.Laparoscopic resection for malignant lymphoma of the ileum causing ileocecal intussusception.Surg Laparosc Endosc Percutan Tech. 2007;17(5):444-6. This article on PubMed

21. Ibrahim EM, Ezzat AA, Ei-Weshi AN, et al.Primary intestinal diffuse large B-cell non- Hodgkin's lymphoma: clinical features, management, and prognosis of 66 patients.Ann Oncol.2001; 12: 53 - 58. This article on PubMed

22. Rackner VL, Thirlby RC, Ryan J A J r.Role of surgery in multimodality therapy for gastrointestinal lymphoma.Am J Surg.1991; 161: 570 - 575. This article on PubMed

23. Samel S, Wagner $\mathrm{J}$, Hofheinz R, et al.Malignant intestinal non-Hodgkin's lymphoma from the surgical point of view.Onkologie.2002; 25: 268 - 271. This article on PubMed

24. Morton J E, Leyland MJ, Vaughan Hudson G, et al.Primary gastrointestinal non-Hodgkin's lymphoma: a review of 175 British National Lymphoma Investigation cases.Br J Cancer.1993; 67: 776 - 782. This article on PubMed

25. Rohatiner A, d'Amore F, Coiffier B, et al.Report on a workshop convened to discuss the pathological and staging classifications of gastrointestinal tract lymphoma.Ann Oncol.1994; 5: 397 - 400. This article on PubMed 